\title{
DIGITAL CONTENTS FOR ENHANCING THE COMMUNICATION OF MUSEUM EXHIBITION: THE PERVIVAL PROJECT
}

\author{
L.L. Micoli, S. Gonizzi Barsanti, G. Caruso, G. Guidi
}

Department of Mechanical Engineering, Politecnico di Milano, Via La Masa 1, 20156

(laura.micoli; sara.gonizzi; giandomenico.caruso; gabriele.guidi)@polimi.it

\section{Commission II}

KEY WORDS: Virtual Reality, Exhibition, Storytelling, Museum, Dissemination, Egyptians, Cultural Heritage.

\begin{abstract}
:
The PERVIVAL project aims at developing an interactive system with the preliminary function of explaining a complex museum collection in a simple and immediate way and allowing the visitor to better understand the museum collection he is about to see. In particular, the interactive system aims at enhancing the understanding of the collections of funeral furnishings of Egyptians, which are characterized by a multiplicity of objects of rich symbolism and connected to each other through complex funeral rituals. The idea is to explain the religious creed of ancient Egyptians through the objects placed in the tomb, having in this way a double benefit: enlightening the rituals and placing the objects back in their primary function. In this way, the knowledge of the visitor is not only enlarged through the description of something that is described on papyruses or inscriptions (hence, not comprehensible) but also the proper function of every single object will be explained through the connection among them, as a function of amulets or goods necessary to travel through the World of the Dead. The connection between the different objects allows a much greater understanding of the exposed collection that would be perceived in this way not as a set of single isolated pieces, but as a harmonious set of complementary elements between they represent a specific historical-cultural context.
\end{abstract}

\section{INTRODUCTION}

\subsection{Overview}

The project aims at creating an interactive virtual environment that has the preliminary function of explaining a complex museum collection in a simple and immediate way and allowing the visitor a better understanding of the museum collection. The virtual visit does not arise as an alternative to the real one, but it would be as an explanatory complement of the descriptive panels distributed in the museum spaces. The virtual storytelling will be based on three-dimensional models of Cultural-Heritage objects exhibited in the museum space or its storehouses. Through a touch screen, the visitor can navigate inside this storytelling connected to the real objects that he can find in the exhibition. The use of 3D models of objects conserved in the storehouse and therefore not accessible for the common public, allows increasing the range of objects publicly available in the exhibition and it can foster new narrative suggestions by enhancing the meaning of the objects physically exhibited in the museum and, in general, the entire design of the display arrangement.

Even if the main idea of the project is the creation of a virtual environment adaptable to any museum collection, such virtual interaction tool will be tested on the Egyptian collection of the Archaeological Museum of Milan, that is going to be rearranged with a new display setting.

The interactive virtual environment will be dedicated to the enhancement and the understanding of the collections of funeral furnishings of Egyptian notables, characterized by a multiplicity of objects of rich symbolism, connected to each other through complex funeral rituals. Egyptian art and culture provide a perfect context for applying the educational and informative innovation, which this project proposal aims to pursue. For example, the writing of the ancient Egyptians, which is incomprehensible to anyone but the experts of Egyptology, is full of meanings and symbols. It explains the function of the pieces that make up the funeral equipment by defining their role within the Egyptian funeral ritual, which is difficult to explain due to its complexity and wholeness, especially if common explanatory tools held by museums are used.

The project idea arose following the new design of the Egyptian exhibition in the Sforza's Castle in Milan. The display area is going to be completely renewed according to a new architectural idea that will allow the visitors to follow an ideal path through the different sections of the ancient Egypt life and the virtual application will be connected to this subdivision. Starting from the point that the virtual environment is considered as a complementary way to explaining the exhibition, the connection between the physical and the virtual space is essential. The virtual history of the events associated with the object illustrated in virtual reality will create a logical path to explain the visit of the collection through its specific historical and narrative elements. Inscriptions, decorative details, stylistic elements, common to the collection or to other contemporary objects, will be highlighted in the virtual models. The connection between the exhibition and the narrative elements should not be linear and repetitive but subjected to different alternative paths based on the visitor's interaction. In this way the objects of this transmedia story, based on contributions of images, videos and interactive 3D models, will no longer be seen as separate elements but they will be part of a narrative path, which will help understanding the motivations of these objects, their use, and their function.

The idea is to explain the religious creed of ancient Egyptians through the objects placed in the tomb, having, in this way, a double benefit: enlightening the rituals and placing the objects back in their primary function. In this way, the knowledge of the visitor is not only enlarged through the description of something, which is described on papyruses or inscriptions (hence, not comprehensible), but also the proper function of every single object will be explained through the connection among them, as the function of amulets or goods necessary to travel through the World of the Dead. The ancient Egyptians had indeed a complex series of beliefs on the afterlife. During the Middle and New 
Kingdom (approximately 2000 to $1000 \mathrm{BC}$ ), it was believed that the cosmos consisted of the earth (the world of the living), the heavens, and an underworld (the world of the dead), called Duat. The funeral marked the transition of the deceased from the world of the living to that of the dead. The tomb consisted of a chapel and a room sealed for the mummy, protected by written spells, representations of gods and magical objects. The world of the dead was a mysterious place that the deceased went through facing various dangers.

A type of ancient source which helps us to understand the beliefs about what the ancient Egyptians should have faced after death, is the text known as the "Book of the Dead". Although there was no single or canonical "Book of the Dead", it generally represents a collection of hundreds of magical spells that the deceased could have used to protect himself from dangers during the journey in the Afterlife. The surviving papyri contain a varying selection of religious and magical texts and vary considerably in their illustration. Some people seem to have commissioned their own copies of the "Book of the Dead" perhaps choosing the spells they thought most vital in their own progression to the afterlife. The "Book of the Dead" was most commonly written in hieroglyphic or hieratic script on a papyrus scroll, and often illustrated with vignettes depicting the deceased and their journey into the afterlife.

The objects of the collection involved in the proposed virtual exhibition are connected to this ritual. The translation of specific hieroglyphics painted on sarcophaguses or engraved on certain objects allows a better understanding of the artefacts and of the ancient tradition. The interconnection between the alphabet, specific images of divinities positioned in key points of the artefacts and other objects on display, allows a better knowledge of the Egyptian religion, and therefore of the culture that produced them.

The 3D models used for the virtual application have been mostly produced from 2012 to 2015 in the framework of the European project 3DICONS using digital photogrammetry (Guidi et al., 2015). The idea of the PERVIVAL project is to reuse these models, with an appropriate post-processing, in order to enhance the dissemination of their information. 3D models are useful as digital documentation, restoration and research but they do not really reach their full accomplishment if not used for dissemination. The work done in the post-processing regarded mainly an accurate topological investigation and correction, and the creation of a high-resolution texture with a balancing of colours, shadows and contrast, in order to obtain an optimal setting for the virtual reality software, where some descriptions and additional information have been added.

\subsection{State of the Art}

A museum is defined by the International Council of Museums (ICOM) as a "non-profit, permanent institution in the service of society and its development, open to the public, which acquires, conserves, researches, communicates and exhibits the tangible and intangible heritage of humanity and its environment for the purposes of education, study and enjoyment" (ICOM, 2007). According to this definition one of the main roles of the museum is not only to conserve cultural heritage, but also to provide and conserve the information related to it (Washburn, 1984; MacDonald, Alsford, 1991).

Such information might be even very extended but the physical limitation of explanatory panels in exhibitions greatly reduces the possibilities to deliver it to the museum's visitors. Several experiences have been done in the past starting from a stronger engagement with the heritage asset (Pletinckx, et al., 2000), or the use of hypermedia to explain a larger amount of information (Alsford, 1991), leading to the concept of "Virtual Museum"
(Schweibenz, 1998). Initially thought more as an Internet accessible information resource, with the introduction of affordable VR and AR interaction tools developed for the videogaming industry, this concept started to be extended to the idea of a digital extension of the physical museum (informative kiosks), available inside it (Styliani et al., 2009).

The introduction of different narrative levels in the virtual environment allows creating links among objects in the exhibition and in storehouses to better explain and interpret the narration (Roussou et al., 2015; Vayanou et al., 2014).

The level of immersion of a virtual exhibition is influenced by the technology used to display digital contents (Carrozzino et al., 2010; Kassahun Bekele et al., 2018). External display systems, such as Power Wall and CAVE, provide the highest level of immersion (Katsouri et al., 2015; Gutierrez et al., 2004; Bruno et al., 2010; Cruz-Neira et al., 1992). Unfortunately, one of the most crucial and problematic factors of these visualization systems is the high cost of the equipment and of the installation. In addition, these display systems are typically stationary, require a lot of space and controlled environment conditions (Reffat et al., 2013). VR interaction technologies and techniques used in $\mathrm{CH}$ are different and can include the use of devices that are able to convey the user's interaction as joysticks, mice, keyboards gesture-based and wearable devices (Fanini, Pagano, 2013).

Although these devices provide a high and engaging level of interaction, often visitors need help in using them (Pietroni et al., 2018). In addition, they could be difficult to integrate within the expositive areas of a museum and they require extra staff helping visitors and for the daily maintenance. Consequently, in this project will exploit the interaction capabilities of commercial touch screens to make the interactive virtual environment reliable and easy to use.

\section{3D MODELLING}

\subsection{D digitization}

The objects chosen for the project have been 3D digitized through photogrammetry (Gonizzi and Guidi, 2013). For the image acquisition two digital reflex cameras were used: a Canon 5D Mark II and a Canon 60D. The Canon 5D features 22 megapixels with a full frame $(36 \times 24 \mathrm{~mm})$ CMOS sensor coupled with a 20 and $50 \mathrm{~mm}$ macro lens. The Canon 60D was equipped with an APS-C $(22.3 \times 14.9 \mathrm{~mm})$ CMOS sensor, featuring 18 megapixels. The lens used in this case were a 20 and a $60 \mathrm{~mm}$ macro. The images were acquired at the highest level for each camera (5616 x 3744 pixels for the 5D, $5138 \times 3456$ for the $60 \mathrm{D}$ ). The distance to which the images were taken varied in the range of $0.5-1.5 \mathrm{~m}$ depending on the physical constrains in the museum, leading to a Ground Sampling Distance (GSD) ranging from $0.06 \mathrm{~mm}$ to $0.48 \mathrm{~mm}$ for the Canon $5 \mathrm{D}$ and $0.04 \mathrm{~mm}$ to $0.33 \mathrm{~mm}$ for the Canon 60D. The image sequences were taken maintaining around $60 \%$ of overlapping between adjacent shots.

The data processing was carried out with the Agisoft Photoscan package matching the oriented images with 1:4 ratio between the GSD and the 3D resolution.

A great attention was given to the quality of color and details in the RAW images, carefully balanced with Adobe Lightroom and exported in JPEG for the photogrammetric processing, and to the resolution of the texture, set at $8 \mathrm{Kx} 8 \mathrm{~K}$.

The choice of the objects was made in agreement with the direction of the Archaeological Museum and the Egyptologists, to follow a hypothetical storytelling flow connected with the new exhibition. The most important part of the application will be the correspondence between the exhibition path and the information provided digitally through the virtual reality application. In this way, each visitor can identify possible objects of interest and 
deepen the information about them without losing the logical sequence of the real exhibit.

\subsection{Post-processing}

The acquired 3D models are triangular meshes that have been post-processed in order to make them suitable for the virtual environment Unity 3D.

The first step regarded a quality check on the topology of the meshes originated by photogrammetry, functional to the following simplification step that allowed to resize the models to be imported in the VR platform. The final step was a reorientation of the model coherent with the logic of Unity 3D.

The tool used for obtaining a closed mesh with no topological errors, that could have influenced the visualization of the models, is the open-source software package MeshLab (Ranzuglia et al., 2012). In the digital content development for the PERVIVAL project several filters are usually applied to the high-resolution mesh originated by the photogrammetric process, such as:

- Remove duplicate faces;

- Remove duplicate vertex;

- Remove faces from non-manifold edges;

- Remove unreferenced vertex;

- Remove zero area faces;

- Select and cancel non-manifold edges;

- Select and cancel non-manifold vertices.

The simplification was performed using the vertex decimation technique to a level compliant with a fluid navigation into the 3D content when imported in Unity3D.

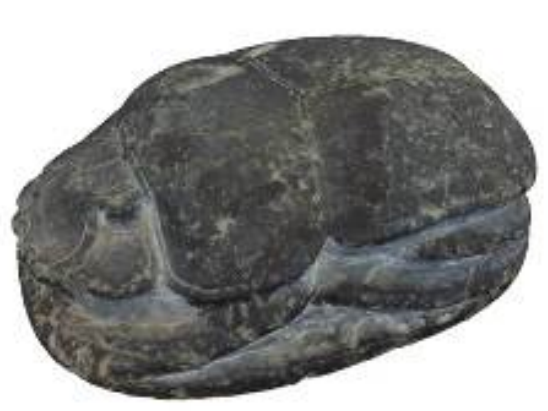

a)

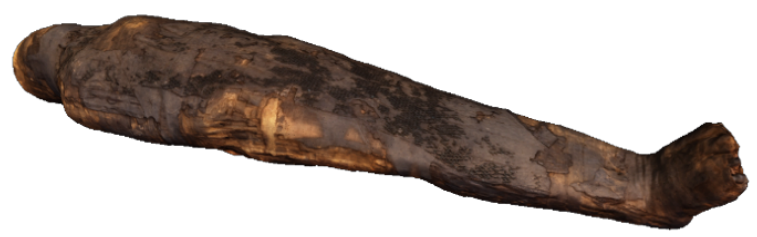

c)

Figure 1. Examples of 3D models finalized for the virtual environment: a) the Scarab of the heart; b) ushabti and c) the male mummy of Peftjauyauyaset

As known, given an initial triangular mesh a vertex decimation technique generates reduced triangular meshes that are anchored on a subset of the initial vertices and optimize fidelity with respect to the original shape. In this work the tool used for the simplification of the 3D models was the module IMCompress in the Innovmetric Polyworks suite (Soucy, 2014).

As a final step the models have been oriented, centred on the $\mathrm{XYZ}$ axes, with $\mathrm{Y}$ vertical, up $\mathrm{X}$ horizontal and $\mathrm{Z}$ exiting from the screen. The barycentre of the model has been translated in correspondence with the origin of the reference system and then the models have been rotated have their frontal face non-oblique and with normal oriented to Z. In this way, the final models were ready to be imported properly in the software for the creation of the virtual environment.

The 3D models will be imported in a virtual environment that is still under construction. The idea is to create different scenes related to the main topic of the exhibition. In this way, the 3D models will have a central role in explaining in an easy way the concepts related to the funerary rituals of the Egyptians. The models will be inserted into different virtual environments with a strong connection among the 3D data, descriptions, images and a back forward correlation that will help and guide the curiosity of the visitor.

Not less important, the virtual application will connect the different object explaining the role of each artefact in the Egyptian tradition, making easier the understanding of the exhibition.

\section{DIGITAL APPLICATION STRUCTURE}

As mentioned, the virtual application will be developed according to museology requirement of the conservator and to the new set-up of the Egyptian exhibition (Mason, 2015).

The old exhibition hall appeared as a long space without limits or rhythm in which the ancient finds were exhibited without particular subdivisions and with a uniform diffused light.

The overall perception was that of a monotonous and passing environment. The new outfitting project has been developed from the Markus Scherer Architect Studio and the light design Studio Ferrara Palladino Lightspace. The main idea is to create a more mystic atmosphere in order to emphasize the value of the archaeological masterpieces (Fig. 2).

The project idea starts from the interpretation of the archetype of a hypostyle hall, characterized by the presence of imposing columns that creates a dense architectural space, to define an exhibition environment that resembles that one. The light will be studied ad hoc for the different exhibition areas in order to emphasize the space rhythm and to highlight the singles pieces. The exhibition will be divided in six main sections:

I. Chronological introduction \& great topics (society/writing/art);

II. Afterlife;

III. Gods and religion;

IV. Excavations in Medinet Madi and Tebtynis;

V. Tolemaic-Roman Egypt;

VI. Copt Egypt.

The virtual application will be mainly connected to the Afterlife section, using the $3 \mathrm{D}$ models of the artefacts as basis for the narration (Fig. 3).

For the ancient Egyptian, it was possible to achieve the eternal life thanks to a complex rituality involving physical and spiritual aspects. It was in fact needed to i) preserve the intact body through the mummification, a sarcophagus, and an appropriate tomb; ii) feed the defunct with real or represented food; iii) face ordeals with the help of rituals, amulets and sarcophagus decorations as described in the papyrus of the "Book of the Dead" that was part of the funerary equipment. 

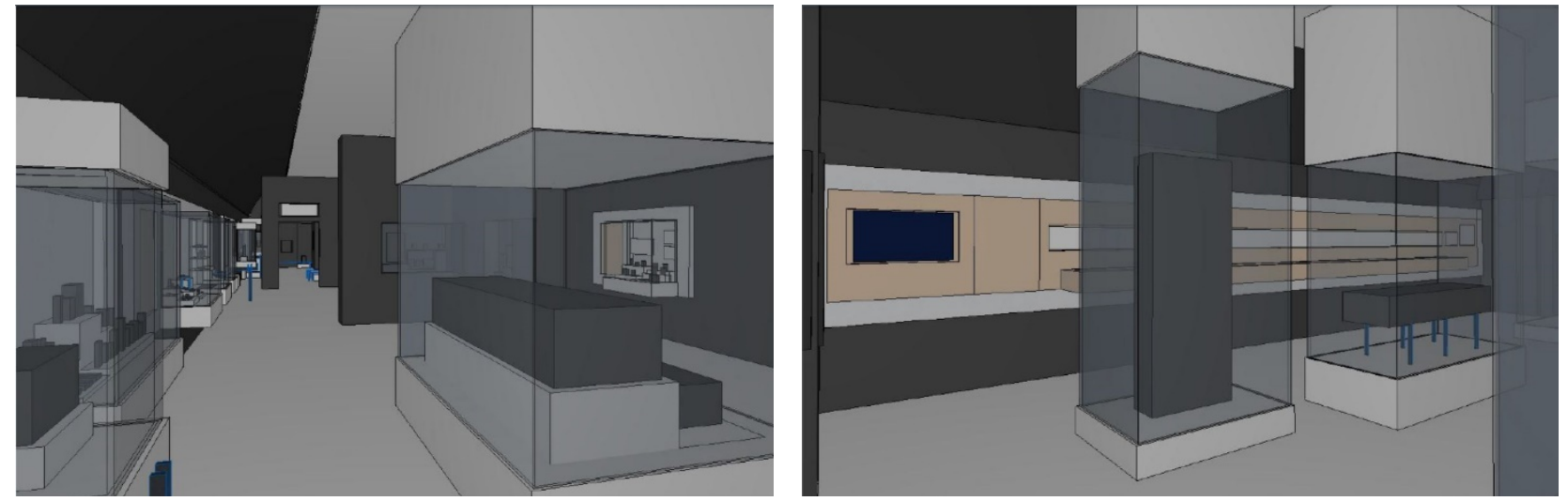

Figure 2. Two renderings of the section Afterlife from the new Egyptian Museum project

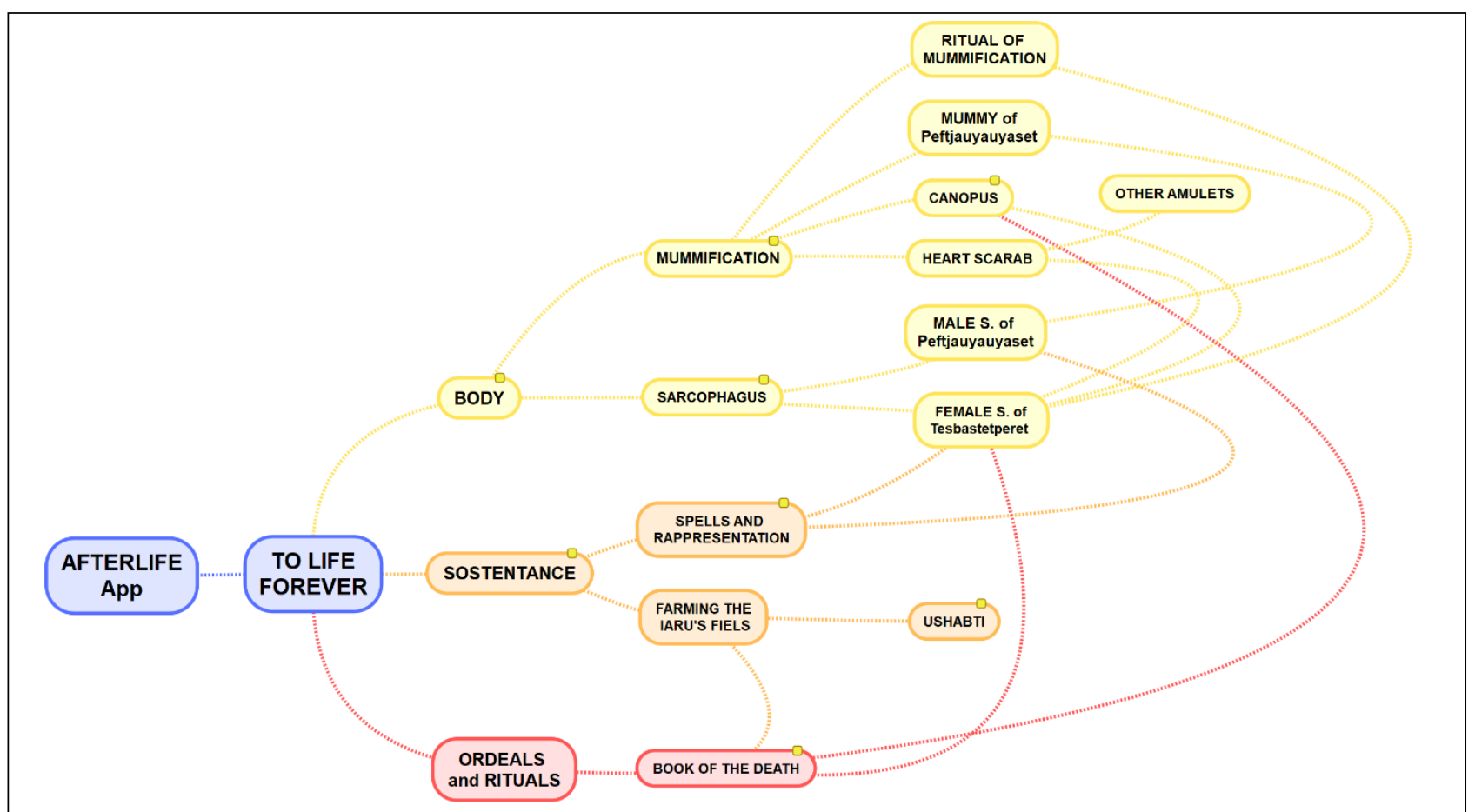

Figure 3. Logical diagram of the contents to be implemented in the interactive digital application

The application will therefore contain three main navigation section, connected each other, related to the themes just described above. The contents will be explained mainly with texturized 3D models of elements from the museum's collection.

The fruition path can be linear, following a predefined and didactic order, or the user can, following his own interests, move from one object to another according to the logical connections between different objects. An example of such connection is shown in figure 4 , where a possible circular link between contents of the digital application is shown. Fig. 4A represents the 3D model of the female anthropoid sarcophagus of Tesbastetperet with the decoration of a mummification ritual highlighted in the centre (Fig. 4A'). In the lower part of figure $4 \mathrm{~A}^{\prime}$ the four Canopic jars used for storing and preserving the viscera of their owner for the afterlife are shown.

They are exactly four because associated with the four sons of the god Horus. These were represented also in the vignette 124 "To go down to the court of Osiris" of the Hornefer papyrus (Fig. 4B) and by the 3D digital replica of the real Canopic jar (Fog. 4C). All the elements are corresponding to a different node of the logical diagram of the application.
The user can manipulate the digital object, exploring it in detail and understanding its meaning within his historical and ritual context. The most interesting aspects will be highlighted through appropriate graphic elements and it will be possible to have detailed interpretative information associated to hieroglyphs or other symbolic representations (Fig. 5).

Special attention will be dedicated to the burial elements of Peftjauyauyaset (VII-VI century BC) of which the museum owns the complete mummy, its anthropoid sarcophagus and the decorated crate where the sarcophagus used to be conserved.

In the physical arrangement, these elements are shown separately for allowing the visitor to enjoy the iconographic richness of the external layers and the good conservation state of the internal mummy. Thanks to the digital application it will be possible to see the artifacts not only from points of view that are inaccessible to the visitor due to the exhibition constraints but also in their original position with one element inside the other.

The user will be able to virtually extract one piece at a time, up to the skeleton level, and investigate it in detail, also displaying contents of recent scientific studies conducted on the mummy with Computer Tomography (CT). 


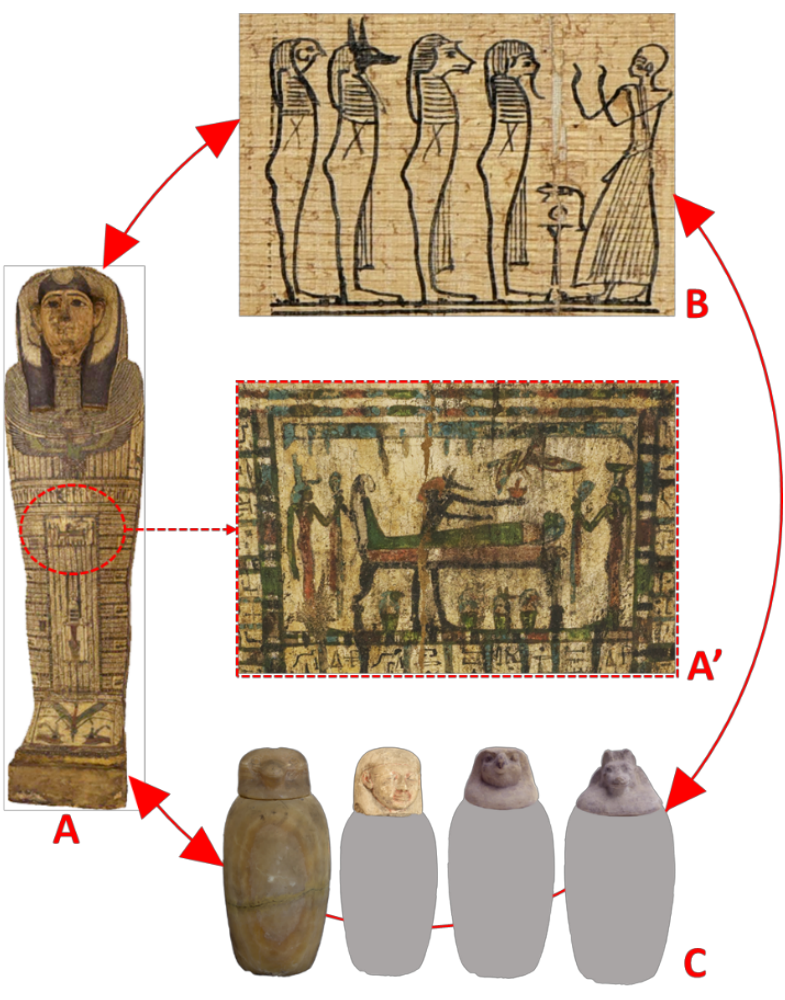

Figure 4. Example of possible circular connection between elements of the digital application. (A) 3D model of the female anthropoid sarcophagus of Tesbastetperet; (A') decoration of a mummification ritual; (B) vignette 124 of the Hornefer papyrus; (C) 3D digital replica of the canopic jars

\section{CONCLUSIONS}

A valid support for museum installations that are at the same time able to "accompany" the visitor within complex collections through narrative paths and to make evident logical elements of connection not immediately deducible from the exhibits, can come from digital applications.

Using 3D digital models, it is possible to generate exhibit products of various kinds, placing in relation several museum pieces through logical elements that make evident connection otherwise difficult to explain with conventional museum exhibits.

In general, the convergence of different types of storytelling and media involved is what Henry Jenkins calls transmedia storytelling (2006), a narrative form that, moving through different types of media, contributes to perfecting and integrating the user experience with complementary information between them. Each medium, conveying new and distinct information, contributes to the development of history and to the understanding of the narrated world. In this way the user is called to reconstruct the overall meaning of a work by integrating various media.

This potential of the narration inside the museum, already present in conventional museography (Bedford, 2001), finds a new and more extensive application if the museum makes use of technologies such as virtual reality for the presentation of its contents, through various integrated forms of digital storytelling (Hartley, McWilliam, 2009). In addition to the multiplication of narrative opportunities favoured by the use of virtual models, the specific importance of dematerialization of cultural heritage once transformed into a digital form becomes fundamental.

The material, in the form of a digital model, can be exhibited by grouping at least virtually collections whose pieces can be placed in different museums or in stores.

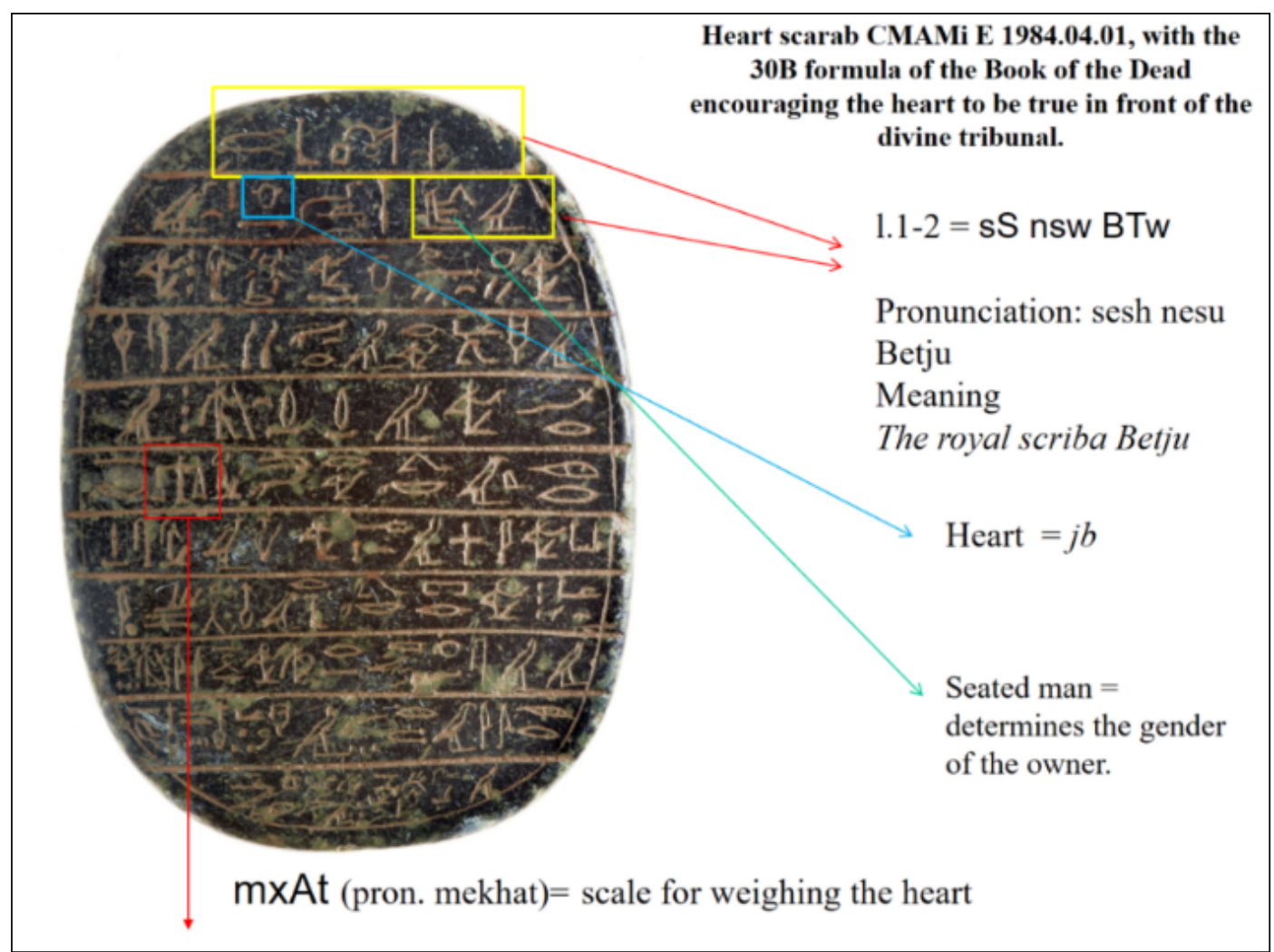

Figure 5. Example of contents that can be highlighted thanks to the 3D digital application: words on Scarab of the Heart, usually placed on the chest of the deceased as an amulet 
This exhibition approach allows the unveiling of pieces not shown at the museum for limitations of the exhibition space and conserved in storage areas not accessible to the public, or because belonging to other museums.

Through virtual technology, a view of the exhibition utterly different from the traditional one can be proposed to the visitor as an informative introduction or an interactive complement to his visit. In this way, the visitor is accompanied by information and insights that will allow him to observe archaeological finds, apparently unrelated to each other, with a different perspective, better understanding what the exhibition presents.

The possibility of creating narratives that link different elements together allows creating different "readings" of the exhibited objects, without necessarily modify the physical layout of the exhibition.

Although the project here described is explicitly referred to ancient Egypt, it is important to emphasize that this technology can be applied to any museum and any subject. Once the skeleton for virtual narration has been created, it can be used for any exhibit, adapting it on the different information and connections of the case.

\section{ACKNOWLEDGEMENTS}

The authors would like to acknowledge Fondazione Cariplo for the financial support and the Archaeological Museum of Milan for giving access to the Egyptian material, with a personal thank to the museum director Anna Provenzali and the Egyptologists Alice Sbriglio and Sabrina Ceruti for the support and the fruitful collaboration.

\section{REFERENCES}

Alsford, S., 1991. Museums as Hypermedia Interactivity on a Museum-wide Scale, in Hypermedia \& Interactivity in Museums, pp. 7-16.

Bedford, L., 2001. Storytelling: the real work of museums. Curator 44, 27-34

Bruno, F., Bruno, S., De Sensi, G., Lughi, M.L., Mancuso, S., Muzzupappa, M., 2010. From 3D reconstruction to virtual reality: a complete methodology for digital archaeological exhibition. Journal of Cultural Heritage 11 (2010) pp. 42-49

Carrozzino, M., and Bergamasco, M., 2010. Beyond virtual museums: Experiencing immersive virtual reality in real museums, J. Cult. Herit., vol. 11, no. 4, pp. 452-458.

Cruz-Neira, C., Sandin, D.J., Defanti T.A., Kenyon R.V., Hart, J.C., 1992. The Cave: audio visual experience automatic virtual environment, Communications of the ACM, Volume 35 Issue 6 , pp. 64-72

Fanini B., and Pagano, A., 2015. Interface design for serious game visual strategies: The case study of 'Imago Bononiae', in 2015 Digital Heritage International Congress, Digital Heritage 2015, pp. 623-626.

Gonizzi Barsanti, S. and Guidi, G., 2013. 3D Digitization of Museum Content within the 3DICONS Project, ISPRS Ann. Photogramm. Remote Sens. Spatial Inf. Sci., II-5/W1, 151-156, https://doi.org/10.5194/isprsannals-II-5-W1-151-2013.

Guidi, G., Barsanti, S.G., Micoli, L.L., Russo M., 2015. Massive 3D Digitization of Museum Contents. In: Toniolo, L., Boriani, M., and Guidi, G. (eds.) Built Heritage: Monitoring Conservation Management. pp. 335-346. Springer.
Gutierrez, D., Seron, F. J., Magallon, J. A., Sobreviela, E. J. and Latorre, P., 2004. Archaeological and cultural heritage: Bringing life to an unearthed Muslim suburb in an immersive environment, J. Cult. Herit., vol. 5, no. 1, pp. 63-74.

Hartley, J., McWilliam, K., 2009. Story circle: digital storytelling around the world. Chichester, UK: Wiley-Blackwell.

ICOM, 2007. ICOM Statute - Internal Rules and Regulations, http://archives.icom.museum/definition.html.

Kassahun Bekele, M., Pierdicca, R., Frontoni, E., Savina Malinverni, E. and Gain, J., 2018. A Survey of Augmented, Virtual, and Mixed Reality for Cultural Heritage. ACM J. Comput. Cult. Herit. 11, 2, Article 7, 36 pages.

Katsouri, I., Tzanavari, A., Herakleous, K. and Poullis, C., 2015. Visualizing and assessing hypotheses for marine archaeology in a VR CAVE environment. J. Comput. Cultur. Herit. 8, 2 (2015), 10 .

Jenkins, H., 2006. Convergence culture: where old and new media collide, New York, New York University Press, ISBN 978-0-8147-4295-2.

MacDonald, G. F. and Alsford, S., 1991. The museum as information utility, Museum Manag. Curatorsh., vol. 10, no. 3, pp. 305-311.

Mason, M., 2015. Prototyping practices supporting interdisciplinary collaboration in digital media design for museums, Museum Management and Curatorship, 30:5, 394426 ,

Pietroni, E., Pagano, A., Fanini, B., 2018. UX Designer and Software Developer at the Mirror: Assessing Sensory Immersion and Emotional Involvement in Virtual Museums. Studies in Digital Heritage Vol. 2, Issue 1, pp. 13-41.

Pletinckx, D., Callebaut, D., Killebrew, A. E. and N. A. Silberman, 2000. Virtual-Reality Heritage Presentation at Ename, IEEE Multimed., vol. 7, no. 2, pp. 45-48.

Ranzuglia, G., Callieri, M., Dellepiane, M., Cignoni, P., Scopigno, R., 2013. MeshLab as a complete tool for the integration of photos and color with high resolution 3D geometry data. In: CAA 2012 Conference Proceedings. pp. 406-416. Pallas Publications - Amsterdam University Press (AUP).

Reffat, R.M., Nofal, E.M., 2013. Effective Communication with Cultural Heritage using Virtual Technologies, International Archives of the Photogrammetry, Remote Sensing and Spatial Information Sciences, Volume XL-5/W2, 2013, Interantional CIPA Symposium, 2-6 September 2013, Strasbourg, France, pp. $519-524$.

Roussou, M., Pujol, L., Katifori, A., Chrysanthi, A., Perry, S., Vayanou, M., 2015. The museum as digital storyteller: Collaborative participatory creation of interactive digital experiences. MW2015: Museums and the Web 2015. Published January 31, 2015. Consulted July 13, 2015. http://mw2015.museumsandtheweb.com/paper/the-museum-asdigital-storyteller-collaborative-participatory-creation-ofinteractive-digital-experiences/

Schweibenz, W., 1998. The "Virtual Museum": New Perspectives For Museums to Present Objects and Information 
Using the Internet as a Knowledge Base and Communication System. In: ISI 1998. pp. 185-199. Prague (1998).

Soucy, M., 2014. InnovMetric's Multiresolution Modelling Algorithms, InnovMetric Software Inc., Jean-Talon Nord, Canada.

Styliani, S., Fotis, L., Kostas, K. and Petros, P., 2009. Virtual museums, a survey and some issues for consideration, J. Cult. Herit., vol. 10, no. 4, pp. 520-528.

Vayanou, M., Katifori, A., Karvounis, M., Kourtis, V., Kyriakidi, M., Roussou, M., Tsangaris, M., Ioannidis, Y., Balet, O., Prados, T., Keil, J., Engelke, T. and Pujol, 2014. L., Authoring Personalized Interactive Museum Stories, in Interactive Storytelling: 7th International Conference on Interactive Digital Storytelling, ICIDS 2014, Singapore, Singapore, November 3-6, 2014, Proceedings, A. Mitchell, C. Fernández-Vara, and D. Thue, Eds. Cham: Springer International Publishing, pp. 37-48.

Washburn, W.E., 1984. Collecting information, not objects, Museum News, vol. 62, no. 3, pp.5-15.

Webel, S., Olbrich, M., Franke, T. and Keil, J., 2013. Immersive experience of current and ancient reconstructed cultural attractions, in Digital Heritage International Congress (DigitalHeritage 2013, vol. 1, pp. 395-398. 